\title{
Human babesiosis, an emerging tick-borne disease in the People's Republic of China
}

\author{
Xia Zhou ${ }^{1,2}$, Shang Xia ${ }^{1}$, Ji-Lei Huang ${ }^{2}$, Ernest Tambo ${ }^{1,3}$, Hong-Xiang Zhuge ${ }^{2^{*}}$ and Xiao-Nong Zhou ${ }^{1 *}$
}

\begin{abstract}
Babesiosis is a typical zoonotic, emerging disease caused by a tick-borne intraerythrocytic protozoan of Babesia spp. that also can be transmitted by blood transfusion. Babesiosis imposes an increasing public-health threat. We reviewed and mapped epidemiological studies on Babesia in vectors and/or rodents in the People's Republic of China (P.R. China) and found that B. microti was the predominant species detected in the investigated regions such as Heilongjiang, Zhejiang, Fujian provinces and Taiwan island. We reviewed a series of sporadic human babesiosis cases collected from 1940's to 2013, in Yunnan, Inner Mongolia, Taiwan and Zhejiang and other regions including a main endemic area of malaria on the China-Myanmar border areas in P.R. China. Clinical manifestations of human babesiosis were also reviewed. Human babesiosis may have previously been overlooked in P.R. China due to a lack of medical awareness and the limitation of clinical diagnostic methods.
\end{abstract}

Keywords: Human babesiosis, Babesia, Emerging disease, P.R. China

\section{Review}

Babesiosis is an intraerythrocytic parasitic and zoonotic disease, caused by Babesia spp. in humans and animals worldwide. Babesia microti-like organisms have been reported to cause illness in Japan, People's Republic of China (P.R. China) and other Asia-Pacific regions. In USA, most documented cases are caused by B. microti, and in Europe by $B$. divergens [1]. Babesiosis is also gaining increasing attention as a potential emerging tickborne zoonosis which can also be transmitted by blood transfusion [2-5]. P.R. China is located in both northern and eastern hemispheres and the distinctive characteristic of China's climate is its variety. The northern region has a subarctic climate, whereas the southern area is dominated by tropical weather, and the climate variability would undoubtedly affect the vector-borne diseases [6,7]. During the last decade new tick-borne infections have emerged and the incidence rate has been rising steadily in several regions of China [8-15]. The latest

\footnotetext{
* Correspondence: hxzhuge@suda.ecu.cn; ipdzhouxn@sh163.net

${ }^{2}$ Department of Parasitology, Medical College of Soochow University, No.199 Renai Road, Suzhou 215123, People's Republic of China

${ }^{1}$ National Institute of Parasitic Diseases, Chinese Center for Disease Control and Prevention, WHO Collaborating Centre for Malaria, Schistosomiasis and Filariasis; Key Laboratory of Parasite \& Vector Biology, Ministry of Health, Shanghai 200025, People's Republic of China

Full list of author information is available at the end of the article
}

research indicated that there is co-prevalence of $B$. microti infections and malaria on the China-Myanmar border areas in Yunnan province in south of P.R. China [16]. Recent studies of cytokine activation and erythrocyte cytoadherence in babesiosis and malaria have exploited these similarities to provide new insights into malaria pathobiology [17]. Meanwhile, the latest information on human babesiosis in P.R. China was examined and the primary question we wanted to address was whether this zoonosis has been sporadic or more widespread than previously appreciated. Our review highlights the challenges of medical awareness of the disease, diagnostic tools and techniques in microbial detection methods, and recommends innovative strategic measures for prevention and control of human babesiosis.

\section{Clinical features, pathogenensis, and diagnosis of babesiosis and malaria}

Both Plasmodium and Babesia species are intraerythrocytic protozoans and elicit similar inflammatory responses [17] with similarities in clinical manifestations including headaches, fever, chills, nausea, vomiting, myalgia, altered mental status, disseminated intravascular coagulation, anaemia with hypotension, respiratory distress, hepatomegaly and renal insufficiency. All symptoms are common to both diseases [18]. Traditionally, 
malaria cases can be diagnosed from a consideration on the basis of a travel history and a careful microscopic or molecular assay [19]. However, the ring forms of Plasmodium falciparum may be difficult to distinguish from the Babesia spp. (Figure 1). Although tetrads of merozoites that are arranged in a cross-like pattern are pathognomonic and provide a typical morphology for diagnosis of babesiosis caused by $B$. microti, it rarely appears as tetrads in human erythrocytes [20].

An infant from the Ivory Coast was suspected of being infected by Babesia $s p$. in Africa who at first was treated as having malaria [21]. Similar co-infection with both agents were reported from experiments using animal models of malaria, the rhesus monkey imported from Guangxi, P.R. China with a suspected infection of $B$. microti-like that originated from a primate-breeding facility [22]. Two cases of febrile patients who were co-infected with Plasmodium and Babesia in malaria endemic areas were detected in our laboratory using molecular epidemiology survey, but the dominant parasite was unclear and to detect species of Plasmodium or Babesia by microscopy in co-infection cases was more difficult [16]. The pathobiology of malaria has been extensively studied in humans; related research on babesiosis is still insufficient. Investigation of similarities and differences in the pathogenesis of babesiosis and malaria could lead to additional fundamental insights for both conditions. Continued investigation of similarities and differences in the pathogenesis of babesiosis and malaria could have broad implications relating to evolutionarily conserved mechanisms of host cell entry in these related apicomplexan parasites and may pave the way toward a detailed molecular understanding of erythrocyte invasion of both pathogens.

In 2005, Lobo et al. reported that B. divergens and P. falciparum use the common receptors, glycophorins $A$ and $B$, to invade the human erythrocyte [23]. Duivenvoorde LM et al. reported that a rhesus macaque chronically infected with $B$. microti was able to control the infection with $P$. cynomolgi better than naïve monkeys [24]. The suppression of a Plasmodium infection after chronic exposure to $B$. microti warrants further investigation for a possible protective role of Babesia infection on Plasmodium.

Babesiosis, recognized as an important disease of domestic animals and more recently as an emerging health problem in humans, is caused by related intraerythrocytic protozoa with a similar pathogenesis and a clinical path.

\section{Current challenges in epidemiological investigation and clinical diagnosis}

Due to the low level parasitemia of babesiosis in the early course of illness, it has been suggested that at least 300 microscopical fields should be reviewed before considering a blood smear free of Babesia. This puts limitations of microscopy diagnosis of babesiosis to be used in the field. Broadly specific PCR for Babesia allows identification of Babesia spp. and differentiate these from Plasmodium infections, hence these tools should be applied to confirm the identity of the pathogens $[16,25]$, however, the molecular methodology is relatively difficult to use in the field surveys because it is more expensive and requires a skilled technologist [26].

All of these three confirmed B. microti-infection patients, either by investigations of smears and/or Babesia specific PCR $[25,27]$ proved that they are very useful tools not only to confirm the correct diagnosis of infection of $B$. microti, but also to monitor the patient's response to antiparasitic therapy.

The most probable mode of infection was from tick bites due to the patients' extensive outdoor recreational activities. One patient received blood products just prior to infection which suggested that the $B$. microti might have been transmitted by blood transfusion [28]. If this was the case, screening of blood donors in this region is urgently needed.

Major problems associated with diagnosing Babesia spp. infections in humans include the general lack of clinical awareness of babesiosis in the medical community, the non-specific clinical manifestations, and the absence of simple and effective rapid diagnostic test (RDT).
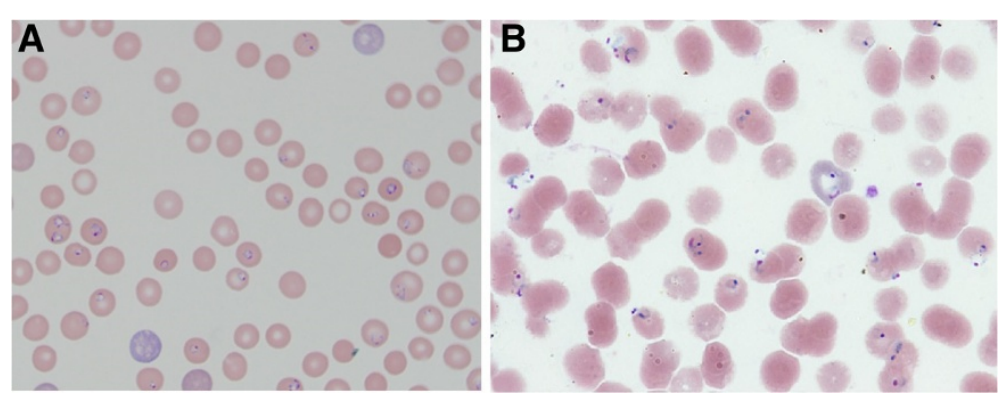

Figure 1 Giemsa-stained thin blood smears showing the similarities of the intraerythrocytic ring form stages of $B$. microti and $P$. falciparum, showing an intraerythrocytic ring form stage of $B$. microti (thick arrow) and ring form stage of $P$. falciparum (thin arrow); Original magnification $\times 1,000$. (A. Ring form stage of $B$. microti, B. Ring form stage of $P$. falciparum). 
Convenient, well-evaluated diagnostic tools such as serological tests or molecular biological assays designed for rapid and reliable detection of such pathogens are not yet readily available to most routine diagnostic laboratories [4]. Additionally, conventional laboratory testresults in clinical cases of human babesiosis may be non-specific, such as high levels of transaminases, alkaline phosphatases, unconjugated bilirubin, and lactic dehydrogenase in addition to normochromia, normocytic anaemia, and thrombocytopenia. Occasionally, leucopenia may also be present, probably owing to a tumour necrosis factor (TNF)-mediated immune response similar to that seen in severe cases of malaria [29].

On the immunological diagnosis of babesiosis, indirect immunofluorescence assay (IFA) is regarded as the standard assay for the detection of Babesia antibody [30]. Another immunological assay by immunoblot for detection of $B$. microti antibody is also available [31]. Luo Y. et al. [32] identified a novel secreted antigen designated as $B$. microti secreted antigen 1 (BmSA1) and found BmSA1 could be a promising and universal target for the serodiagnosis of human babesiosis and for an epidemiological survey. Ooka H. et al. [33] applied an ELISA using rBmP94/ CT for diagnosis of B. microti infection, and it demonstrated high sensitivity and specificity when tested with the sera from mice experimentally infected with $B$. microti and other species of Babesia. These results indicated that BmSA1 and BmP94/CT could be potential markers for surveillance of human babesiosis caused by B.microti. However, to date, serological studies on population tick exposure to Babesia have not been conducted and the diagnostic value of these antigens to human babesiosis has not been evaluated. In New England (Country) where the disease is enzootic, to evaluate acute babesiosis cases, an immunofluorescent assay (IFA) was carried out. The sensitivity of the IFA was $91 \%$, the specificity was $99 \%$, the positive predictive value was $86 \%$, and the negative was $99 \%$. So IFA should be a sensitive, specific routine clinical diagnosis of acute and convalescent babesiosis [34]. The latest survey on seroprevalence of blood donors was carried out in Babesia endemic areas of the Northeast and Upper Midwest in the USA. The presence of antibodies against B. microti was tested by using an IFA. The results showed that $2 \%(42 / 2150)$ of the donors were positive and one patient was confirmed to have an ongoing infection of Babesia by positive PCR (1/42) [35]. The ELISA survey on the febrile cases were applied by diagnostic antigen of BmSA1 expression and purified in our group to conduct the prevalence of the human babesiosis. The results showed that BmSA1 have cross-reactivity with malaria cases in China. The former seroprevalence survey in Babesia endemic areas of the Northeast and Upper Midwest in the USA showed that most of the sero-positive cases
(41/42) were negative in the molecular survey. Thus, clinical diagnosis of human babesiosis can be further complicated by persistent low parasitemia or asymptomatic latent infections, particularly in malaria and babesiosis syndemic areas.

\section{Evidence for occurrence of vectors, reservoir hosts and pathogenic B. microti in P.R. China}

There are many babesiosis natural foci areas where Babesia spp. in ticks or/and other reservoir hosts are found in P.R. China. B. microti-like rodent parasite was isolated from the tick, Ixodes persulcatus, and collected from the northern forest area of Heilongjiang province, P.R. China [36]. Field rodent surveys for Babesia infections performed from 2002 to 2005 in the vicinities of human babesiosis cases in southeastern of P.R. China confirmed the presence of Kobe strain of B. microti in rodents from Zhejiang, Fujian and Taiwan [37]. In 2012, Jiang et al. [38] carried out a survey on the infection of Babesia protozoa in rodents in Chun'an County, Zhejiang province and reported cases of human babesiosis using molecular detection. The molecular survey demonstrated that $B$. microti infections were present in two Rattus tanezumi and one $R$. norvegicus. The results were in accordance with the distribution of $B$. microti in the vicinities where human babesiosis occurred in the P.R. China [14].

I. persulcatus is regarded as the most important vector for human tick-borne diseases in P.R. China and there is anecdotal evidence that $I$. persulcatus can transmit $B$. microti and $B$. divergens to both humans and animals [1]. A molecular survey in Heilongjiang province showed that of all the obtained Babesia infections in I. persulcatus, $78 \%$ of ticks were infected with B. microti; the remaining $22 \%$ with $B$. divergens. The second important tick, Haemaphysalis concinna, $82 \%$ were infected with $B$. microti and $18 \%$ of $B$. divergens $[39,40]$. Another molecular survey carried out in Jilin province revealed that B. microti-infections were the main strain in I. persulcatus with an infection rate of $5 \%(20 / 379)$ [41], indicating that $B$. microti may be the dominant Babesia species in northeastern regions of China. Furthermore, the molecular survey in Inner Mongolia Autonomous Region demonstrated that Dermacentor nuttallia was the predominant tick species with a $66 \%(29 / 44)$ rate of infection with $B$. divergens and $34 \%(15 / 44)$ with $B$. microti [42]. A molecular survey by the broadly specific primers for hemoprotozoa in Piroplasma on the tick-borne pathogen infection rate in wild rodents in eight sites in Xinjiang Uygur Autonomous Region was carried out. Of all the positive infections of Babesia or Theileria (53/ $165)$ samples, only $6 \%(3 / 53)$ of the wild rodents were confirmed to be infected with $B$. microti, and the remaining were infections of Theileria spp. This 
indicates that B. microti-infections were not the predominant species in Xinjiang Uygur Autonomous Region [43]. In 2008, B. microti-like parasites were identified in one rhesus monkey (Macaca mulatta) imported from Guangxi Zhuang Autonomous Region and the suspected infection of $B$. microti originated from a primatebreeding facility [22]. This provided anecdoctal evidence of the presence of natural foci of B. mciroti in Guangxi Zhuang Autonomous Region. B. microti was also detected from $I$. persulcatus in Beijing and the partial sequences of $18 \mathrm{~S}$ RNA gene of $B$. microti was submitted to NCBI GenBank (accession no. JX962781). Recently, a total of 33 rodents (22 Apodemus agrarius and $11 R$. norvegicus) were captured from Xinyang City, Henan province. Inoculation experiments were carried out in mice and indicated that one of the rodents was co-infected with A. phagocytophilum and B. microti [44]. Thus, the detection and isolation of both pathogens from the single rodent in Henan province further highlighted the possibility of coinfection in human beings and should alert public health. In summary, previous epidemiological studies on Babesia infections in vectors or rodents by universal primers for Babesia spp. has shown that the occurrence of pathogenic Babesia spp. exists widely in P.R. China. Specific PCR confirmed that B. microti infections were the predominant species in southeastern and northeastern of P.R. China while $B$. divergens and other Babesia species may be the main pathogen genus of Babesia in Inner Mongolia [42] and Xinjiang Uygur Autonomous Region of P.R. China [43] (Table 1 and Figure 2).

\section{Evidence of $B$. microti infection in humans and non-human primates in China}

Human babesiosis is characterized as an emerging disease and the severity of Babesia infection is variable, ranging from an asymptomatic infection to severe life threatening disease depending on the host immune status and species of infecting Babesia. Severe babesiosis generally occurs in patients who are immune-compromised including the persons who are over 50 years old, with malignancy, HIV or immunosuppressive medication [1]. Current limitations of light microscopy diagnosis make it difficult to differentiate the ring forms of $P$. falciparum and Babesia spp. clinically [1]. The co-prevalence of $B$. microti infections and malaria on the China-Myanmar border areas in Yunnan province of southwestern China during April, 2012 to June, 2013 were found in farmers who involved in outdoor activities in the forests or mountains, or in individuals with other underlying diseases and/or have had blood transfusion or other blood products [16]. The investigation carried out in Europe demonstrated that less than $50 \%$ of tick bites are

Table 1 Positive ratio of $B$. microti detection in reservoir hosts or ticks in China

\begin{tabular}{|c|c|c|c|c|c|c|}
\hline \multirow[b]{2}{*}{ Province } & \multirow[b]{2}{*}{ Site } & \multicolumn{2}{|c|}{ Species of hosts or vectors } & \multirow{2}{*}{$\begin{array}{l}\text { Infection rate, } \% \\
\text { (Positive no./examined no.) }\end{array}$} & \multirow{2}{*}{$\begin{array}{l}\text { Reported } \\
\text { human babesiosis } \\
\text { cases }\end{array}$} & \multirow[t]{2}{*}{ References } \\
\hline & & Ticks & Rodents & & & \\
\hline \multirow[t]{2}{*}{ Heilongjiang } & \multirow{2}{*}{$\begin{array}{l}\text { Mohe port Suifenhe } \\
\text { port }\end{array}$} & \multirow{2}{*}{$\begin{array}{l}\text { lxodes persulcatus, } \\
\text { Haemaphysalis } \\
\text { concinna }\end{array}$} & $N / A^{*}$ & \multirow[t]{2}{*}{$3.4(13 / 383)$} & \multirow[t]{2}{*}{ No } & \multirow{2}{*}{$\begin{array}{l}\text { Yang LW et al. } \\
\text { [40]; Fu WM et al. } \\
\text { [39] }\end{array}$} \\
\hline & & & N/A & & & \\
\hline Jilin & Changbai port & 1. persulcatus & N/A & $5.3(20 / 379)$ & No & Pu Y et al. [41] \\
\hline Beijing & / & 1. persulcatus & N/A & $\mathrm{N} / \mathrm{A}$ & No & $\begin{array}{l}\text { NCBI, } 2011 \\
\text { GenBank, no. } \\
\text { JX962781 }\end{array}$ \\
\hline Inner Mongolia & $\begin{array}{l}\text { Ceke port,Mandula } \\
\text { port, Manzhouli port }\end{array}$ & Dermacentor nuttallia & $\mathrm{N} / \mathrm{A}$ & $1.2(15 / 1303)$ & Yes & Hao GF et al. [42] \\
\hline Guangxi & / & $\mathrm{N} / \mathrm{A}$ & $\begin{array}{l}\text { Macaca } \\
\text { mulatta }\end{array}$ & $\mathrm{N} / \mathrm{A}$ & No & $\begin{array}{l}\text { Voorberg-vd Wel. A } \\
\text { et al. [22] }\end{array}$ \\
\hline Henan & Xinyang & $\mathrm{N} / \mathrm{A}$ & $\begin{array}{l}\text { Rattus } \\
\text { norvegicus }\end{array}$ & $9.1(1 / 11)$ & No & Zhao X et al. [44] \\
\hline \multirow[t]{2}{*}{ Zhejiang } & Hangzhou & $\mathrm{N} / \mathrm{A}$ & $\begin{array}{l}\text { R. tanezumi, } R \text {. } \\
\text { norvegcus }\end{array}$ & $2.8(3 / 106)$ & Yes & Jiang LP et al. [38] \\
\hline & Tiantai Mountain & $\mathrm{N} / \mathrm{A}$ & $\begin{array}{l}\text { Niviventer } \\
\text { confucianus }\end{array}$ & $50.0(4 / 8)$ & Yes & Saito-Ito et al. [37] \\
\hline Fujian & Wuyi Mountain & $\mathrm{N} / \mathrm{A}$ & N. confucianus & $33.3(6 / 18)$ & No & Saito-Ito et al. [37] \\
\hline Taiwan & Nantou, Gaohsiung & $\mathrm{N} / \mathrm{A}$ & $\begin{array}{l}\text { R. coxinga, } \\
\text { Citellus } \\
\text { horsefieldii }\end{array}$ & $5.1(2 / 39)$ & Yes & Saito-Ito et al. [37] \\
\hline Xinjiang & $\begin{array}{l}\text { Wuchai wan, Fuhai, } \\
\text { Bulzin, Hanashi Lake }\end{array}$ & $\mathrm{N} / \mathrm{A}$ & $\begin{array}{l}\text { C. erythrogenys } \\
\text { Lagurus luteus }\end{array}$ & $1.8(3 / 165)$ & Yes & Zamoto et al. [43] \\
\hline
\end{tabular}

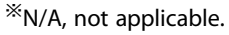




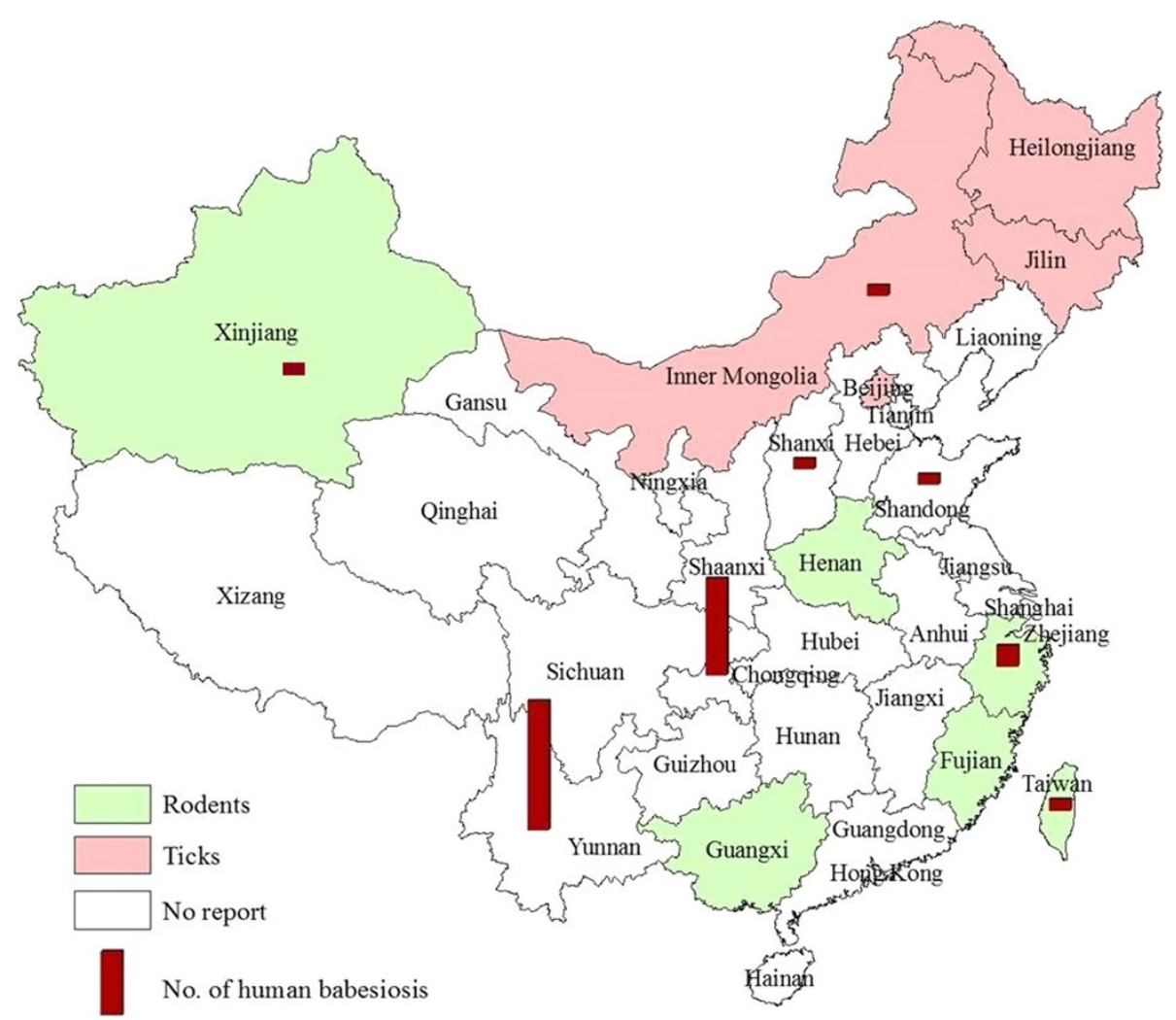

Figure 2 Geographic areas where endemic areas of human babesiosis and ixodes tick vectors or wild rodents infected with $B$. microti in China. Light green colors denote areas where the rodents that acted as the reservoir hosts in transmitting Babesia were detected; Pink colors denote areas where ixodes tick vectors transmitting Babesia were detected; Red pillars denote areas where human babesiosis reported, height of the pillars denote the number of reported babesiosis cases. White colors designate areas where no survey been carried on Babesia in ticks or rodents, despite some areas with reported human babesiosis cases.

documented in individuals who commonly do professional or recreational outdoor activities, and frequently suffer from several tick-bites each year [45]. As such, the prevalence of pathogens in ticks and tick exposure are important risk factors for acquiring infections with tickborne organisms, which may explain the significantly higher seroprevalence in high risk groups compared with blood donors [46,47]. The prevalence of Babesia in ticks and rodents and sporadic human babesiosis cases, have been investigated or reported in several provinces or regions in P.R. China (Figure 2).

A series of surveys in areas including Xinjiang Uygur Autonomous Region [43], Heilongjiang province [36,39,40], Jilin province [41], Inner Mongolia Autonomous Region [42], Henan province, Zhejiang province [38], Fujian province, Taiwan [37], and Guangxi Zhuang Autonomous Region [22] demonstrated the presence of Babesia in ticks or animals (Figure 2). These areas investigated above appear to be natural foci of piroplasms and may present a hazard to public health. Hence, systematic studies on seroprevalence in the population should be carried out in potentially infected humans in P.R. China.
During 1931 to 1944, Hung S.L. et al. [48] produced a series of reports on human parasitemia in Beibei, Chongqing, P.R. China, with the protozoa present in human erythrocytes described as being similar to ring form stages of $P$. falciparum but having fundamental differences in size (smaller) and no pigment, therefore strongly indicating that they were Babesia. These reports were available 13 years earlier than the first case describing human babesiosis reported in a Yugoslavian farmer in 1957 [49], and may be the first report of human babesiosis. In 1969, the first case of human babesiosis caused by $B$. microti spp. with $I$. scapularis as vectors was reported in an immunocompromised patient on Nantucket Island, off the coast of Massachusetts in USA [50]. Sporadic human babesiosis cases have been documented in Yunnan, Inner Mongolia, Taiwan, Zhejiang, Shanxi and other regions in China from 1984 to 2013 [12-14,27,51-53]. The latest study demonstrated that an 8 years old febrile child was infected by $B$. venatorum from Xinjiang Uygur Autonomous Region and the sequencing results showed that $B$. venatorum is closely related to $B$. divergens [54]. In summary, assuming the cases reported by Hung et al. [48] were 
human babesiosis, about a third of the 27 human babesiosis cases that have been reported in China were occured before 1980 and two thirds thereafter (Figure 3). All of these cases presented with fever and chills and three with severe hepatosplenomegaly. B. microti infection may be asymptomatic in about half of children and a quarter of adults [55]. Furthermore, clinical manifestations are typically non-specific, so the diagnosis may have been missed for a long period of time. Recently, a small-scale epidemic of babesiosis was reported in the malaria-endemic areas of the China-Myanmar border in Yunnan province, where the risk of acquiring Babesia spp. either from ticks or from human blood products was previously unknown [16].

Most of the cases reported from China were previously diagnosed solely on the basis of detection of parasites in blood smears by microscopy, a method that does not allow for confirmation of species identity. Case reports which included methods for molecular identification of the pathogen, suggest the presence of Babesia spp. not previously reported from China. Of all reported sporadic human babesiosis cases in China from 1984 to 2014, 16 were identified as Babesia species including 14 identified $[14,16,27]$ as $B$. microti and 2 as B. divergens-like [54,56]. Meanwhile, based on the information of reported babesiosis cases more than half of these cases were originally infected in south or southeast of China including Taiwan island (Table 2 and Figures 2 and 3).

The presence of $B$. microti and B. divergens in ticks and reservoir hosts has been documented (Table 1), but there are no well documented serological studies to confirm the exposure to such agents in tick-infested individuals in China (Table 2). A recent genetic analysis of $B$. microti isolates sampled throughout the USA and Eurasia revealed that this organism represents a genetically diverse species complex [57]. On that basis it has been argued that local variability in the prevalence of Babesia spp. in ticks, along with differences in transmissibility and virulence of strains in some geographic areas may explain the lack of clinical cases in humans, despite the local presence of these agents in competent enzootic cycles [47,57]. In addition, lack of medical awareness, may also lead to significant underreporting of human cases in many regions of P.R. China. Correspondingly, the recent occurrence of two ignored indigenous cases of human babesiosis on the ChinaMyanmar border areas in Tengchong, Yunnan province, is of great medical interest as this is an area where such infections have never been reported. Of these two cases, one had even received transfusion and blood products for treatment of complications. The patient recalled multiple tick bites in the recent past which made this case more complicated [58]. Another confirmed and well documented autochthonous case of $B$. microti infection was reported in 1996 from Taiwan [27]. The patient was a 51-year-old woman from a rural area (Min-Shung, Chia-i Hsien) in southwestern Taiwan and diagnosis of B. microti infection was also established by specific PCR and sequencing.

To observe genetic sequence differences of $B$. microti detected in China and other countries, we aligned sequences of $18 \mathrm{~S}$ rRNA (about 1628-1634 bp) and betatubulin gene (about $579 \mathrm{bp}$ ) fragments of B. microti from a variety of vertebrate hosts (humans, wood mouse,

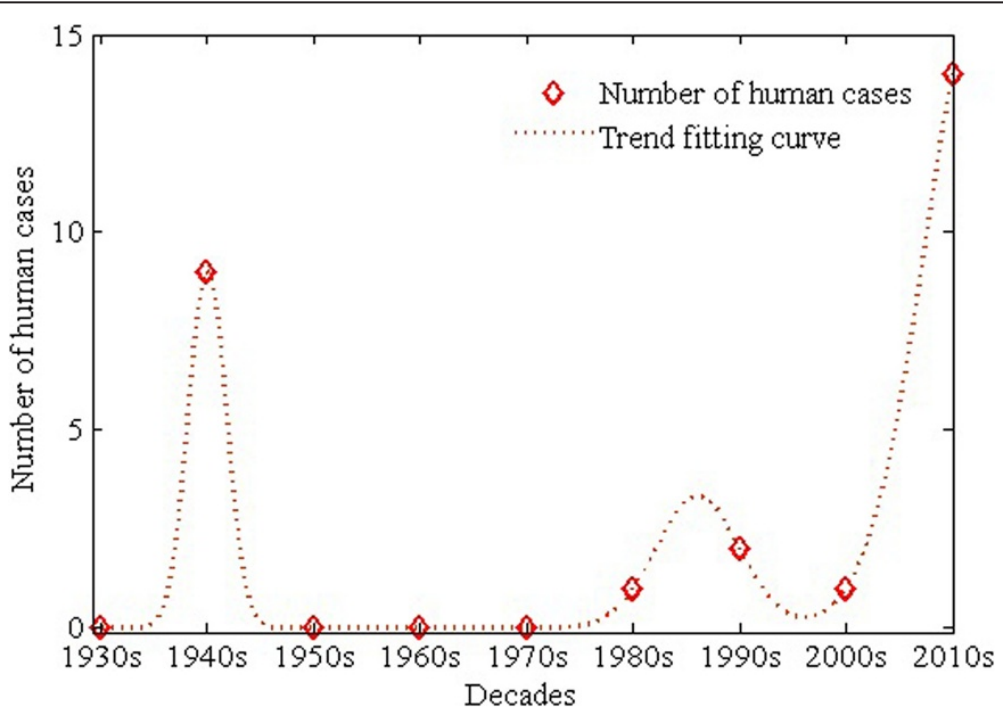

Figure 3 Human babesiosis cases reported in China from 1930s up to 2013. Tread fitting curve denotes the development of human babesiosis cases from 1930s to 2014. Totally, assuming the cases reported by Hung et al. were human babesiosis, about 27 babesiosis cases that have been reported in China. About a third of the 27 babesiosis cases that have been reported in China were occurred before 1980 which were focused during 1940s and two thirds thereafter. 
Table 2 Reported human babesiosis cases in China

\begin{tabular}{|c|c|c|c|c|c|c|}
\hline Province & Species & $\begin{array}{l}\text { Number of } \\
\text { reported cases }\end{array}$ & Clinical manifestation & $\begin{array}{l}\text { Other underlying } \\
\text { diseases in } \\
\text { patients }\end{array}$ & $\begin{array}{l}\text { Reported investigation } \\
\text { of reservoir } \\
\text { hosts or ticks }\end{array}$ & References \\
\hline Chongqing & Unidentified & 9 & Chills \& Febrile & Unclear & No & Hung SL [48] \\
\hline \multirow[t]{4}{*}{ Yunnan } & Unidentified & 1 & Chills \& Febrile & Unclear & No & Li JF et al. [51] \\
\hline & \multirow[t]{2}{*}{ Unidentified } & 2 & Chills \& Febrile, & \multirow[t]{2}{*}{ Severe diarrhea } & \multirow[t]{2}{*}{ No } & \multirow[t]{2}{*}{ Wang HX [13] } \\
\hline & & 8 & arthralgias & & & \\
\hline & B. microti & & $\begin{array}{l}\text { Chills \& Febrile, } \\
\text { arthralgias }\end{array}$ & $\begin{array}{l}\text { History of renal } \\
\text { insufficiency } \\
\text { caused by malaria }\end{array}$ & No & $\begin{array}{l}\text { Zhou X et al. } \\
2013[16,58]\end{array}$ \\
\hline Inner Mongolia & Unidentified & 1 & $\begin{array}{l}\text { Chills \& Febrile, } \\
\text { arthralgias }\end{array}$ & Unclear & Yes & Shi ZB et al. [52] \\
\hline Taiwan & B. microti & 1 & $\begin{array}{l}\text { Chills \& Febrile, } \\
\text { hepatosplenomegaly }\end{array}$ & Gallstones & Yes & Shih CM et al. [27] \\
\hline \multirow[t]{2}{*}{ Zhejiang } & Unidentified & 1 & Chills \& Febrile & $\begin{array}{l}\text { Renal failure \& renal } \\
\text { transplantation }\end{array}$ & Yes & Su GG et al. [12] \\
\hline & B. microti & 1 & $\begin{array}{l}\text { Anemia, Chills \& Febrile, } \\
\text { hepatosplenomegaly }\end{array}$ & $\begin{array}{l}\text { History of lumpectomy } \\
\text { \& hysterectomy }\end{array}$ & Yes & Yao LN et al. [14] \\
\hline Shandong & B. divergens & 1 & unclear & Anemia & No & Qi CH et al. [56] \\
\hline Shanxi & Unclear & 1 & $\begin{array}{l}\text { Chills \& Febrile, } \\
\text { hepatosplenomegaly }\end{array}$ & Disc herniation & No & $\begin{array}{l}\text { Shanxi Daily } \\
\text { news } 2013 \text { [53] }\end{array}$ \\
\hline Xinjiang & $\begin{array}{l}\text { B. venatorum } \\
\text { (B. divergens-like) }\end{array}$ & 1 & Anemia \& Febrile & No & Yes & Sun $Y$ et al. [54] \\
\hline
\end{tabular}

raccoons and rhesus monkey etc.) or from ticks collected in China. These were compared with cases reported in several other countries, such as USA, Spain, Switzerland, Russia, Japan, Korea, and Australia. Phylogenetic trees of maximum-likelihood analysis depicting the relationships of the $18 \mathrm{~S}$ rRNA gene and beta-tubulin gene of B. microti were constructed by MEGA 5.0. Distances were estimated by the Kimura 2-parameter model and the numbers above the branch demonstrate bootstrap support from 1000 replications. The 18S rRNA gene and beta-tubulin gene sequence of $P$. falciparum fragile (JQ627152 and M31205) were included in the trees as outgroups. According to the pathogenesis and the host, B. microti has three different clades. It was regarded as a genetically diverse species complex [59]. Clade 1 of $B$. microti contained mostly rodent parasites and also the majority of these strains thought to be zoonotic; Clade 2 contained carnivore parasites and Clade 3 contained rodent parasites which are probably not zoonotic. To identify the isolates reported in China, we carried out the analyses of phylogenetic relationships of $B$. microti strains using maximum-likelihood analyses based on the 18S rRNA partial gene about 1628 bp-1634 bp and beta-tubulin partial gene about 579 bp of Babesia.

The sequences of beta-tubulin gene of $B$. microti isolated from raccoon or monkeys from Xinjiang Uygur Autonomous Region, China (AB083378) [43], Guangxi Zhuang Autonomous Region, China (EU168706) [19] and Beijing, China (AB731449) have closer phylogenetic relationships than those (KJ128385, KJ128387) isolated from humans. The sequences of $18 \mathrm{~S}$ rRNA genes of $B$. microti isolated from humans in Yunnan and Zhejiang provinces, China have the closer phylogenetic relationships with those isolated from Japan and Switzerland. Most of $B$. microti in China appear to be in Clade 1 which was thought to include the zoonotic strains (Figure 4). The alignment results on 18s RNA gene between strains of $B$. microti detected from febrile patients on China-Myanmar border areas, Zhejiang, Taiwan in China, Japan and some strains detected in wildlife rodents were demonstrated in the Additional file 1 and beta-tubulin gene alignment of B. microti strains in patients from the ChinaMyanmar border areas, Australia and Babesia-strains detected in neighboring wildlife rodents were listed in the Additional file 2.

\section{Conclusions}

Currently, little data is available on the prevalence of Babesia spp. in ticks or rodents in P.R. China [15]. Further sero-epidemiological and molecular epidemiological studies are urgently needed to learn more about the true distribution and medical relevance of these pathogens in various parts of P.R. China.

Clearly, laboratories in babesiosis endemic areas of P.R. China need better access to modern diagnostic methods for a more rapid and reliable microbiological diagnosis in cases of suspected human babesiosis [26,60]. Detection 

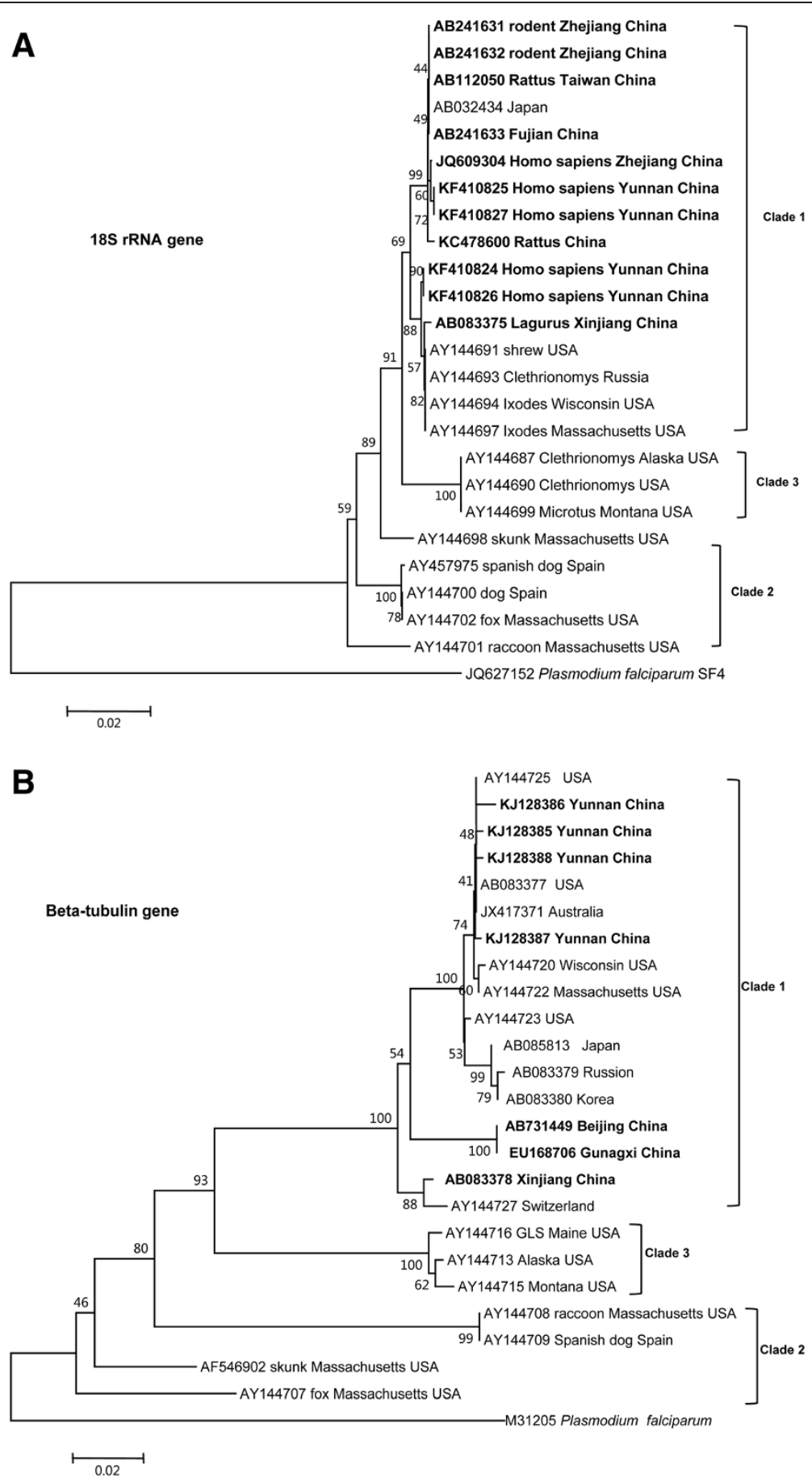

Figure 4 Phylogenetic relationships of $B$. microti strains using maximum-likelihood analysis by MEGA 5.0. Distances were estimated by the Kimura 2-parameter model and the numbers above the branch demonstrate bootstrap support from 1000 replications. The 185 rRNA gene and beta-tubulin gene sequence of $P$. falciparum fragile (JQ627152 and M31205) were included in the trees as outgroups. A. based on sequences coding $18 \mathrm{~S}$ rRNA gene of B. microti; B. based on sequences coding beta-tubulin gene of B. microti, (originated from Goethert HK and Telford SR, 3rd [59], and modified from Zhou $X$ et al. [58].

of the asymptomatic but chronically infected blood donors may be useful in preventing -transmitted babesiosis in areas where Babesia spp. has zoonotic potential $[61,62]$.
Notably, babesiosis and malaria have similarities and differences in the pathogenesis relating to mechanisms of host cell entry in apicomplexan parasites [23] and the coinfection cases of babesiosis and malaria showed that both 
diseases appear to be endemic on the China-Myanmar border $[42,63,64]$. This research approach should pave the way towards successfully controlling both pathogens based on the molecular analysis of erythrocyte invasion.

\section{Additional files}

\section{Additional file 1: 18s RNA gene alignment results between strains of $B$. microti detected from febrile patients on China-Myanmar border areas babesiosis Zhejiang in P.R. China, Japan and some strains detected in wildlife rodents. \\ Additional file 2: Beta-tubulin gene alignment of $B$. microti strains in patients from the China-Myanmar border areas, Australia and Babesia-strains detected in neighboring wildlife rodents.}

\section{Competing interest}

The authors declared that they have no competing interests.

\section{Authors' contributions}

XZ and XNZ conceived the study, collected the data and analyzed it, and drafted the manuscript. SX, JLH and ET conceived the project and provided technical support for data collection and analysis. HXZG and XNZ conceived the study and revised the manuscript. All authors read and approved the final manuscript.

\section{Acknowledgment}

This project was supported by National Natural Science Foundation of China (grant No. 81273192). Zhou XN was supported by Special Fund for Health Research in the Public Interest (grant No. 201202019) and the National S\&T Major Program (grant No. 2012ZX10004220).

We would express our sincere gratitude to Dr. Li Mei from the malaria department of National Institute of Parasitic Diseases, China CDC for provide the Giemsa stain slides of $P$. falciparum in Figure $2 B$.

We would express our sincere gratitude to Dr. Merritt Christine from Wisconsin, USA for helping to review the manuscript and editing the language.

\section{Author details}

${ }^{1}$ National Institute of Parasitic Diseases, Chinese Center for Disease Control and Prevention, WHO Collaborating Centre for Malaria, Schistosomiasis and Filariasis; Key Laboratory of Parasite \& Vector Biology, Ministry of Health, Shanghai 200025, People's Republic of China. ${ }^{2}$ Department of Parasitology, Medical College of Soochow University, No.199 Renai Road, Suzhou 215123, People's Republic of China. ${ }^{3}$ Biochemistry Department, Centers for Sustainable Malaria Control, Faculty of Natural \& Agricultural Sciences, University of Pretoria, Pretoria, South Africa.

Received: 1 February 2014 Accepted: 28 October 2014

Published online: 18 November 2014

\section{References}

1. Vannier E, Krause PJ: Human babesiosis. N Engl J Med 2012, 366(25):2397-2407.

2. Homer MJ, Aguilar-Delfin I, Telford SR 3rd, Krause PJ, Persing DH: Babesiosis, Clin Microbiol Rev 2000, 13(3):451-469.

3. Hunfeld KP, Hildebrandt A, Gray JS: Babesiosis: recent insights into an ancient disease. Int J Parasitol 2008, 38(11):1219-1237.

4. Lobo CA, Cursino-Santos JR, Alhassan A, Rodrigues M: Babesia: an emerging infectious threat in transfusion medicine. PLoS Pathog 2013, 9(7):e1003387.

5. Herwaldt BL, Linden JV, Bosserman E, Young C, Olkowska D, Wilson M: Transfusion-associated babesiosis in the United States: a description of cases. Ann Intern Med 2011, 155(8):509-519.

6. Bi Y, Yu W, Hu W, Lin H, Guo Y, Zhou XN, Tong S: Impact of climate variability on Plasmodium vivax and Plasmodium falciparum malaria in Yunnan Province, China. Parasit Vectors 2013, 6:357.

7. Li T, Yang Z, Wang M: Temperature, relative humidity and sunshine may be the effective predictors for occurrence of malaria in Guangzhou, southern China, 2006-2012. Parasit Vectors 2013, 6:155.
8. Chen XP, Cong ML, Li MH, Kang YJ, Feng YM, Plyusnin A, Xu J, Zhang YZ: Infection and pathogenesis of Huaiyangshan virus (a novel tick-born bunyavirus) in laboratory rodents. J Gen Virol 2012, 93(Pt6):1288-1293.

9. Zhang YZ, Zhou DJ, Xiong Y, Chen XP, He YW, Sun Q, Yu B, Li J, Dai YA Tian JH, Qin XC, Jin D, Cui Z, Luo XL, Li W, Lu S, Wang W, Peng JS, Guo WP, Li MH, Li ZJ, Zhang S, Chen C, Wang Y, De Jong MD, Xu J: Hemorrhagic fever caused by a novel tick-borne bunyavirus in Huaiyangshan, China. Chin J Epidemiol 2011, 32(3):209-220 (in Chinese).

10. Xu B, Liu L, Huang X, Ma H, Zhang Y, Du Y, Wang P, Tang X, Wang H, Kang K, Zhang SQ, Zhao GH, Wu WL, Yang YH, Chen HM, MuF CWJ: Metagenomic analysis of fever, thrombocytopenia and leukopenia syndrome (FTLS) in Henan Province, China: discovery of a new bunyavirus. PLoS Pathog 2011, 7(11):e1002369.

11. Si BY, Jiang $T$, Zhang $Y$, Deng $Y Q$, Huo $Q B$, Zheng $Y C$, Qin $E D$, Qin $C F$, Zhu QY: Complete genome sequence analysis of tick-borne encephalitis viruses isolated in northeastern China. Arch Virol 2011, 156(8):1485-1488.

12. Su GG, Zhao NF, Ye YX: A babesia case report. Chin J of Zoon 2002, 18:112-155 (in Chinese).

13. Wang HX: One case of babesiosis in Kunming. Int J Med Parasit Dis 2012, 39:190-192 (in Chinese).

14. Yao LN, Ruan W, Zeng CY, Li ZH, Zhang X, Lei YL, Lu QY, Che HL: Pathogen identification and clinical diagnosis for one case infected with Babesia. Chin J Parasitol Parasit Dis 2012, 30(2):118-121 (in Chinese).

15. Wu XB, Na RH, Wei SS, Zhu JS, Peng HJ: Distribution of tick-borne diseases in China. Parasit Vectors 2013, 6:119.

16. Zhou X, Li SG, Chen SB, Wang JZ, Xu B, Zhou HJ, Ge HX, Chen JH, Hu W: Co-infections with Babesia microti and Plasmodium parasites along the China-Myanmar border. Infect Dis Poverty 2013, 2(1):24.

17. Krause PJ, Daily J, Telford SR, Vannier E, Lantos P, Spielman A: Shared features in the pathobiology of babesiosis and malaria. Trends Parasitol 2007, 23(12):605-610

18. Clark IA, Jacobson LS: Do babesiosis and malaria share a common disease process? Ann Trop Med Parasitol 1998, 92(4):483-488

19. Rodgers SE, Mather TN: Human Babesia microti incidence and Ixodes scapularis distribution, Rhode Island, 1998-2004. Emerg Infect Dis 2007 13(4):633-635

20. Vannier E, Gewurz BE, Krause PJ: Human babesiosis. Infect Dis Clin North Am 2008, 22(3):469-488. viii-ix.

21. Vermeil C, Menut J, Miegeville M, Cruziat J, Julienne F, Morin O, Roger AP, Marjolet M, Bouillard C: Babesiasis, pediatric malaria: does confusion exist in Africa? Bull Soc Pathol Exot Filiales 1983, 76(5 Pt 2):797-804.

22. Voorberg-vd Wel A, Kocken CH, Zeeman AM, Thomas AW: Detection of new Babesia microti-like parasites in a rhesus monkey (Macaca mulatta) with a suppressed Plasmodium cynomolgi infection. Am J Trop Med Hyg 2008, 78(4):643-645.

23. Lobo CA: Babesia divergens and Plasmodium falciparum use common receptors, glycophorins $A$ and $B$, to invade the human red blood cell. Infect Immun 2005, 73(1):649-651.

24. van Duivenvoorde LM, Voorberg-van der Wel A, van der Werff NM, Braskamp G, Remarque EJ, Kondova I, Kocken CH, Thomas AW: Suppression of Plasmodium cynomolgi in rhesus macaques by coinfection with Babesia microti. Infect Immun 2010, 78(3):1032-1039.

25. Persing DH, Mathiesen D, Marshall WF, Telford SR, Spielman A, Thomford JW, Conrad PA: Detection of Babesia microti by polymerase chain reaction. J Clinl Microbiol 1992, 30(8):2097-2103.

26. Chen JH, Wang H, Chen JX, Bergquist R, Tanner M, Utzinger J, Zhou XN: Frontiers of parasitology research in the People's Republic of China: infection, diagnosis, protection and surveillance. Parasit Vectors 2012, 5:221.

27. Shih CM, Liu LP, Chung WC, Ong SJ, Wang CC: Human babesiosis in Taiwan: asymptomatic infection with a Babesia microti-like organism in a Taiwanese woman. J Clin Microbiol 1997, 35(2):450-454.

28. Rosenblatt JE: Laboratory diagnosis of infections due to blood and tissue parasites. Clin Infect Dis 2009, 49(7):1103-1108.

29. Mylonakis E: When to suspect and how to monitor babesiosis. Am Fam Physician 2001, 63(10):1969-1974.

30. Krause PJ, Telford SR 3rd, Ryan R, Conrad PA, Wilson M, Thomford JW, Spielman A: Diagnosis of babesiosis: evaluation of a serologic test for the detection of Babesia microti antibody. J Infect Dis 1994, 169(4):923-926.

31. Ryan R, Krause PJ, Radolf J, Freeman K, Spielman A, Lenz R, Levin A: Diagnosis of babesiosis using an immunoblot serologic test. Clin Diagn Lab Immunol 2001, 8(6):1177-1180. 
32. Luo Y, Jia H, Terkawi MA, Goo YK, Kawano S, Ooka H, Li Y, Yu L, Cao S, Yamagishi J, Fujisaki K, Nishikawa Y, Saito-Ito A, Igarashi I, Xuan X: Identification and characterization of a novel secreted antigen 1 of Babesia microti and evaluation of its potential use in enzyme-linked immunosorbent assay and immunochromatographic test. Parasitol Int 2011, 60(2):119-125.

33. Ooka H, Terkawi MA, Goo YK, Luo Y, Li Y, Yamagishi J, Nishikawa Y, Igarash I, Xuan X: Babesia microti: molecular and antigenic characterizations of a novel 94-kDa protein (BmP94). Exp Parasitol 2011, 127(1):287-293.

34. Krause PJ, Ryan R, Telford S 3rd, Persing D, Spielman A: Efficacy of immunoglobulin $\mathrm{M}$ serodiagnostic test for rapid diagnosis of acute babesiosis. J Clin Microbiol 1996, 34(8):2014-2016.

35. Tonnetti L, Thorp AM, Deisting B, Bachowski G, Johnson ST, Wey AR, Hodges JS, Leiby DA, Mair D: Babesia microti seroprevalence in Minnesota blood donors. Transfusion 2013, 53(8):1698-1705.

36. Sun Y, Liu G, Yang L, Xu R, Cao W: Babesia microti-like rodent parasites isolated from Ixodes persulcatus (Acari: Ixodidae) in Heilongjiang Province, China. Vet Parasitol 2008, 156(3-4):333-339.

37. Saito-Ito A, Takada N, Ishiguro F, Fujita H, Yano Y, Ma XH, Chen ER: Detection of Kobe-type Babesia microti associated with Japanese human babesiosis in field rodents in central Taiwan and southeastern mainland China. Parasitology 2008, 135(6):691-699.

38. Jiang LP, Zhang L, QH B, QY L, SY C, Xu BX: Babesia DNA segments detected from rodents in Zhejiang province. Chin J Vector Biol Control 2012, 23:303-305 (in Chinese).

39. Fu WM, He H, Hu MX, Cui Y, Yang L: Babesia microti-like rodent parasites isolated from Ixodes persulcatus (Acari: Ixodidae) at China -Russia ports of Heilongjiang Province. Chin Front Heal Quarant 2010, 33:99-104 (in Chinese).

40. Yang LW, Hou Y, Li M, Wen ZQ, Yang J, Fan D: Study of tick-borne pathogens at Heilongjiang port. Chin Front Heal Quarant 2007, 30:77-82 (in Chinese).

41. Pu Y, Li J, Song XH, Li BG, Ma CZ, Li BX, Yang HN: Detection and analysis on important ticks and tick-borne pathogen at Jilin port areas, China. Acta Parasitol Med Entomol Sin 2009, 16(4):228-232 (in Chinese).

42. Hao GF, Li H, Sun Y, Ge RP, Qiao GQ, Li B, Tian WZ, Shi NX, Yang XY: Detection of tick and tick-borne pathogen in some ports of Inner Mongolia. Chin J Epidemiol 2009, 30(4):365-367 (in Chinese).

43. Zamoto A, Tsuji M, Wei Q, Cho SH, Shin EH, Kim TS, Leonova GN, Hagiwara K, Asakawa M, Kariwa H, Takashima I, Ishihara C: Epizootiologic survey for Babesia microti among small wild mammals in northeastern Eurasia and a geographic diversity in the beta-tubulin gene sequences. J Vet Med Sci 2004, 66(7):785-792.

44. Zhao XG, Li H, Sun Y, Zhang YY, Jiang JF, Liu W, Cao WC: Dual infection with Anaplasma phagocytophilum and Babesia microti in a Rattus norvegicus. China. Ticks Tick Borne Dis 2013, 4(5):399-402 (in Chinese).

45. Wilske B, Fingerle V: Diagnosis of Lyme borreliosis. How to corroborate suspected borreliosis. MMW Fortschr Med 2000, 142(15):28-31.

46. Hunfeld KP, Lambert A, Kampen H, Albert S, Epe C, Brade V, Tenter AM: Seroprevalence of Babesia infections in humans exposed to ticks in midwestern Germany. J Clin Microbiol 2002, 40(7):2431-2436.

47. Hunfeld KP, Brade V: Zoonotic Babesia: possibly emerging pathogens to be considered for tick-infested humans in Central Europe. Int J Med Microbiol 2004, 293(Suppl 37):93-103.

48. Hung SL: Notes on a species of malaria parasite finding from Bei-Bei. Nat Med J Chin (Chongaing ed) 1944, 19:571-573 (in Chinese).

49. Skrabalo Z, Deanovic Z: Piroplasmosis in man; report of a case. Doc Med Geogr Trop 1957, 9(1):11-16.

50. Western KA, Benson GD, Gleason NN, Healy GR, Schultz MG: Babesiosis in a Massachusetts resident. N Engl J Med 1970, 283(16):854-856.

51. Li JF, Meng DB, Wang QF: The discovery of human babesiasis. Chin J Vet Med 1984, 6:19-20 (in Chinese)

52. Shi ZB, Li ZZ, Gao QR, Ding YM: One case of human babesia infection. Chin J Parasitol Parasit Dis 1996, 14:240 (in Chinese).

53. Shanxi Daily News: Men suffering from a rare babesiosis swelled such as pregnant women. 2013, http://www.sxdaily.com.cn/n/2013/0715/c3495174146/html (in Chinese).

54. Sun Y, Li SG, Jiang JF, Wang X, Zhang Y, Wang H, Cao WC: Babesia venatorum infection in child. Emerg Infect Dis 2014, 20(5):896-897.

55. Krause PJ, McKay K, Gadbaw J, Christianson D, Closter L, Lepore T, Telford SR 3rd, Sikand V, Ryan R, Persing D, Radolf JD, Spielman A: Increasing health burden of human babesiosis in endemic sites. Am J Trop Med Hyg 2003, 68(4):431-436.

56. Qi C, Zhou D, Liu J, Cheng Z, Zhang L, Wang L, Wang Z, Yang D, Wang S, Chai T: Detection of Babesia divergens using molecular methods in anemic patients in Shandong Province, China. Parasitol Res 2011, 109(1):241-245.

57. Telford SR 3rd, Goethert HK: Emerging tick-borne infections: rediscovered and better characterized, or truly 'new'? Parasitology 2004, 129(Suppl):S301-S327.

58. Zhou X, Li SG, Wang JZ, Huang JL, Zhou HJ, Chen JH, Zhou XN: Emergence of human babesiosis along the border of China with Myanmar: detection by PCR and confirmation by sequencing. Emerg Microb Infect 2014, 3:e55.

59. Goethert HK, Telford SR 3rd: What is Babesia microti? Parasitology 2003, 127(Pt 4):301-309.

60. Chen Z, Liu Q, Jiao FC, Xu BL, Zhou XN: Detection of piroplasms infection in sheep, dogs and hedgehogs in Central China. Infect Dis Poverty 2014, 3:18.

61. Tambo E, Ai L, Zhou X, Chen JH, Hu W, Bergquist R, Guo JG, Utzinger J, Tanner M, Zhou XN: Surveillance-response systems: the key to elimination of tropical diseases. Infect Dis Poverty 2014, 3:17.

62. Zhou XN: Prioritizing research for "One health - One world". Infect Dis Poverty 2012, 1:1.

63. Tambo E, Adedeji AA, Huang F, Chen JH, Zhou SS, Tang LH: Scaling up impact of malaria control programmes: a tale of events in Sub-Saharan Africa and People's Republic of China. Infect Dis Poverty 2012, 1:7.

64. Bi Y, Tong S: Poverty and malaria in the Yunnan Province, China. Infect Dis Poverty 2014, 3:32.

doi:10.1186/s13071-014-0509-3

Cite this article as: Zhou et al:: Human babesiosis, an emerging tick-borne disease in the People's Republic of China. Parasites \& Vectors 2014 7:509.

\section{Submit your next manuscript to BioMed Central and take full advantage of:}

- Convenient online submission

- Thorough peer review

- No space constraints or color figure charges

- Immediate publication on acceptance

- Inclusion in PubMed, CAS, Scopus and Google Scholar

- Research which is freely available for redistribution 